\title{
RESTRUKTURISASI ORGANISASI PADA SEKERTARIAT DAERAH KABUPATEN ENDE PROVINSI NUSA TENGGARA TIMUR
}

\author{
Pius Mithe ${ }^{1}$, Heru Nurasa ${ }^{2}$, Sawitri Budi Utami ${ }^{3}$ \\ ${ }^{1}$ Mahasiswa Pasca Sarjana Administrasi Publik, FISIP, Universitas Padjajaran \\ Email : piusmithe@gmail.com \\ ${ }^{2}$ Dosen pada Departemen Administrasi Publik, FISIP, Universitas Padjajaran \\ Email : hnurasa@yahoo.com \\ ${ }^{3}$ Dosen pada Departemen Administrasi Publik, FISIP, Universitas Padjajaran \\ Email : sawitribudiutami@gmail.com
}

\begin{abstract}
This paper discusses the process of organizational restructuring that occurred at the Regional Secretariat of Ende District as a result of the policy of regional apparatus arrangement in Ende District, East Nusa Tenggara Province. Although it has gone through various changes, a number of regulatory tools have been replaced with the consequences of changing the concept of organizational restructuring from downsizing to rightsizing, but have not been able to significantly improve the performance of the Regional Secretariat of Ende District. In this study the author uses the concept of restructuring derived from the $4 R$ theory (Gouilarrt \& Kelly, 1995) with the indicators namely building an organizational model, integrating physical infrastructure, and redesigning the work architecture. The research method used is descriptive with a qualitative approach that is carried out through observation and interviews and reinforced secondary data studies from relevant agency documents and the results of previous competent research. The results show that indicators build economic models, integration of physical infrastructure, and redesign the work architecture have not run optimally. The restructuring was apparently not balanced with the availability of human resources and pre-facility facilities as well as good financial management.
\end{abstract}

Keywords: Regional Secretariat of Ende District, Restructuring, Local Government Organization 


\section{PENDAHULUAN}

Reformasi pelayanan sektor publik merupakan hal yang tidak dapat dihindari untuk dilakukan oleh pemerintah demi memenuhi tuntutan kepuasan masyarakat sebagai pelanggan. Dalam rangka merespon hal tersebut maka pemerintah harus dituntut dapat memperbaiki kinerja organisasi publik agar dapat bertahan hidup dan memberikan pelayanan maksimal kepada masyarakat. Pengembangan organisasi merupakan jawaban terhadap perubahan dan merupakan strategi yang kompleks dalam merubah susunan organisasi agar selalu efektif dan dinamis (Bennis \& Mische, 2005).

Seiring dengan perubahan paradigma pemerintahan yang bergeser dari sentralistik kepada desentralistik dengan pemberlakuan otonomi daerah, maka tuntutan perubahan struktur organisasi (restrukturisasi) pemerintahan daerah agar dapat bertahan hidup adalah konsekuensi logis yang harus dijalani demi pencapaian good governance (Wasistiono, 2002; Indrajit, 2006) . Oleh karena itu maka pemerintah pusat melakukan langkah penyesuaian dengan melakukan upaya restrukturisasi perangkat daerah (PD) melalui serangkaian kebijakan penataan PD yang kemudian diimplementasikan melalui penetapan peraturan daerah tentang susunan organisasi PD.

Restrukturisasi PD pada era otonomi daerah dimulai dengan pemberlakuan PP 84 Tahun 2000 tentang pedoman organisasi perangkat daerah. Selanjutnya kehadiran Undang Undang Nomor 32 Tahun 2004 tentang Pemerintahan Daerah sebagai revisi dari Undang Undang Nomor 22 Tahun 1999 tentang Pemerintahan Daerah, juga menyertakan perubahan struktur PD yang tertuang dalam Peraturan Pemerintah Nomor 41 Tahun 2007 tentang Pedoman Organisasi Perangkat Daerah. Peraturan tersebut kemudian dicabut setelah ditetapkannya Undang Undang Nomor 23 Tahun 2014 tentang Pemerintahan Daerah yang juga menyertai lahirnya Peraturan Pemerintah nomor 18 Tahun 2016 tentang Perangkat Daerah.

Sekertariat Daerah Kabupaten Ende sebagai salah satu PD pemerintah Kabupaten Ende yang memiliki fungsi sentral sebagai koordinator PD tingkat Kabupaten Ende juga mengalami dampak restrukturisasi sesuai dengan perubahan kebijakan diatas. Adanya perubahan tersebut terlihat dari penambahan struktur pada tingkat bagian dan sub bagian, yang sebelumnya berjumlah 9 (sembilan) bagian menjadi 12 (duabelas) bagian dan sub bagian dari 27 (dua puluh tujuh) menjadi 36 (tiga puluh enam).

Selain pembengkakan struktur, kebijakan restrukturisasi belum berdampak signifikan pada kinerja Sekertariat Daerah Kabupaten Ende secara langsung. Hal ini terlihat pada hasil LAKIP (Laporan Akuntabilitas Kinerja Instansi Pemerintah) Sekertariat Daerah Kabupaten Ende tahun 2016 dan 2017 yang cenderung "stagnan".

Berdasarkan fenomena diatas, maka perlu dilakukan penelitian lebih mendalam mengenai restrukturisasi organisasi pada Sekertariat Daerah Kabupaten Ende. Dengan harapan bahwa hasil penelitian ini dapat menjadi bahan masukan berharga bagi pemerintah Kabupaten Ende dalam mewujudkan optimalisasi kinerja Sekertariat Daerah Kabupaten Ende.

\section{METODE PENELITIAN}

Untuk menganalisis restrukturisasi organisasi pada Sekertariat Daerah Kabupaten Ende, diperlukan penelitian secara mendalam yang mampu mengungkapkan memahami fenomenafenomena yang bersumber dari dinamika restrukturisasi organisasi, olehnya pendekatan kualitatif dengan metode analisis deskriptif dipilih, dengan pertimbangan bahwa pendekatan kualitatif merupakan prosedur penelitian yang berusaha untuk menggambarkan pandangan, persepsi peneliti secara menyeluruh yang berhubungan dengan data yang diperoleh di lapangan.

Sumber data dari penelitian ini terdiri atas data primer dan sekunder yang diperoleh dari hasil observasi, wawancara, dan dokumentasi. Dan untuk pemilihan informan, dipilih berdasarkan pada pandangan (Koentjaraningrat, 1991), yaitu orang yang diwawancarai merupakan orang yang benar-benar menguasai dan mengetahui sepenunhya mengenai permasalahan yang akan 
diteliti. Oleh karena itu informan dalam penelitian terdiri dari pegawai dari instansi pemerintah yang berkompeten dalam proses restrukturisasi Sekertariat Daerah Kabupaten Ende.

Dokumentasi dalam penelitian ini perlu dilakukan untuk memperkuat hasil penelitian. Dokumentasi yang dimaksud dalam hal ini berupa dokumen-dokumen berharga. Fakta dan data yang diperoleh dalam lokasi penelitian sebagian besar tersimpan dalam bentuk dokumentasi. Untuk analisis data menggunakan teknik analisis data yang dikemukakan oleh (Miles \& Huberman, 1994) yang disebut interactive model, dimana terdiri atas reduksi data (data reduction), penyajian data (data display), dan penarikan serta pengujian kesimpulan (drawing and verifying concluctions).

\section{HASIL DAN PEMBAHASAN}

1. Membangun Model Organisasi (Constructuring The Organization Models)

Sebagai tahapan awal dari proses restrukturisasi, maka Constructuring The Organization Models memiliki peranan yang cukup penting. Penyusunan model kerja organisasi diharap mampu menggambarkan, memposisikan dan membangun model organisasi dari level tertinggi ke level yang terendah sehingga mampu menjadi teamwork yang utuh dan saling bersinergi serta termotivasi (Simangunsong, 2001). Adapun tujuan dari hal ini adalah struktur organisasi dapat memberikan tingkat efisiensi yang tinggi tanpa merugikan pelanggan dan memberikan keuntungan maksimal bagi organisasi.

Dalam proses perubahan struktur organisasi sesuai Peraturan Pemerintah Nomor 18 Tahun 2016, pemerintah daerah diharuskan melakukan pemetaan urusan dan proses tipelogi perangkat daerah sebagai syarat mutlak pembentukan PD. Hal ini juga diterapkan pada Sekretariat Daerah Kabupaten Ende. Adapun hasil pemetaan yang telah dilakukan antara lain sebagai berikut

Tabel 1. Rekapitulasi Variabel dan Urusan Penunjang Pemerintahan Kabupaten Ende

\begin{tabular}{|l|l|l|l|l|l|l|}
\hline No & $\begin{array}{l}\text { Urusan Penunjang } \\
\text { Pemerintahan }\end{array}$ & \multicolumn{2}{l|l|}{ Skor Variabel } & $\begin{array}{l}\text { Total } \\
\text { Skor }\end{array}$ & $\begin{array}{l}\text { Beban } \\
\text { Kerja }\end{array}$ & Tipe \\
\cline { 3 - 4 } & & Umum & Teknis & & & \\
\hline 1. & Sekretariat Daerah & 160 & 690 & 850 & Besar & A \\
\hline 2. & Sekretariat DPRD & 160 & 480 & 640 & Sedang & B \\
\hline
\end{tabular}

Sumber : Bagian Organisasi Setda Kabupaten Ende Tahun 2016

Berdasarkan tabel 1 diatas dapat diketahui bahwa hasil pemetaan menetapkan Sekretariat Daerah Kabupaten Ende termasuk dalam kategori tipe A (beban kerja besar ) dengan skor 850. Pada pasal 74 PP Nomor 18 Tahun 2016 dinyatakan bahwa : " sekretariat daerah kabupaten/kota tipe A terdiri atas paling banyak 3 (tiga) asisten, masing-masing asisten dapat membentuk paling banyak 4 (empat) bagian dan masing- masing bagian bisa membentuk 3 (tiga) sub bagian ". Hal inilah yang kemudian mendorong pemerintah Kabupaten Ende menggunakan skala maksimal dalam pembentukan unit kerjanya. Kebijakan ini tentunya termuat dalam Peraturan Daerah Kabupaten Ende Nomor 11 Tahun 2016 tentang Pembentukan dan Susunan Perangkat Daerah Kabupaten Ende. Untuk memahami perubahan struktur organisasi tersebut dapat dilihat pada tabel 2 berikut :

Tabel 2 . Perbandingan Susunan Organisasi Sekretariat Daerah Kabupaten Ende

\begin{tabular}{|l|l|l|l|}
\hline No & \multicolumn{1}{|c|}{ Unsur } & \multicolumn{3}{|c|}{ Ruang Lingkup Koordinasi } \\
\cline { 3 - 4 } & & Perda No.5 tahun 2008 & Perda No.11 tahun 2016 \\
\hline 1. & $\begin{array}{l}\text { Asisten Pemerintahan dan } \\
\text { Kesejahteraan Rakyat }\end{array}$ & $\begin{array}{l}\text { 1. Bagian Pemerintahan } \\
\text { Umum }\end{array}$ & $\begin{array}{l}\text { 1. Bagian Pemerintahan } \\
\text { dan Otda }\end{array}$ \\
\hline
\end{tabular}




\begin{tabular}{|c|c|c|c|}
\hline & & $\begin{array}{l}\text { 2. Bagian Kesejahteraan } \\
\text { Rakyat } \\
\text { 3. Bagian Humas }\end{array}$ & $\begin{array}{l}\text { 2. Bagian Kesejahteraan } \\
\text { Rakyat } \\
\text { 3. Bagian Hukum } \\
\text { 4. Bagian Pemberdayaan } \\
\text { Masyarakat \& } \\
\text { Trantibum }\end{array}$ \\
\hline 2. & $\begin{array}{l}\text { Asisten Perekonomian dan } \\
\text { Pembangunan }\end{array}$ & $\begin{array}{l}\text { 1. Bagian Pembangunan } \\
\text { 2. Bagian Ekonomi } \\
\text { 3. Bagian Pemberdayaan } \\
\text { Perempuan }\end{array}$ & $\begin{array}{l}\text { 1. Bagian Ekonomi } \\
\text { 2. Bagian Humas \& } \\
\text { Protokoler } \\
\text { 3. Bagian Administrasi } \\
\text { Pembangunan } \\
\text { 4. Bagian Pengadaan } \\
\text { Barang dan Jasa }\end{array}$ \\
\hline 3. & Administrasi & $\begin{array}{l}\text { 1. Bagian Organisasi \& } \\
\text { Kepegawaian } \\
\text { 2. Bagian Hukum } \\
\text { 3. Bagian Umum }\end{array}$ & $\begin{array}{l}\text { 1. Bagian Organisasi } \\
\text { 2. Bagian Umum } \\
\text { 3. Bagian Kepegawaian } \\
\text { 4. Bagian Keuangan \& } \\
\text { Aset }\end{array}$ \\
\hline
\end{tabular}

Sumber : Data Olahan Peneliti Tahun 2017

Dari tabel 1.2 diatas dapat diketahui adanya beberapa perubahan pada struktur organisasi Sekretariat Daerah Kabupaten Ende sesuai Perda Nomor 11 tahun 2016 tentang Pembentukan dan Susunan Perangkat Daerah Kabupaten Ende. Hal yang menarik adalah terdapat pengembangan struktur dengan terbentuknya 12 (dua belas) bagian dan 36 (tiga puluh enam) sub bagian. Jika dibandingkan dengan aturan sebelumnya, yakni Peraturan Daerah Nomor 5 Tahun 2008 yang merupakan kebijakan derivat dari Peraturan Pemerintah Nomor 41 Tahun 2007 tentang Organisasi Perangkat Daerah, maka terdapat pengembangan struktur yang cukup signifikan pada sekretariat daerah Kabupaten Ende. Hal ini juga terlihat pada jumlah jabatan struktural yang sebelumnya hanya terdiri atas 9 (sembilan) orang pejabat yang menduduki eselon III (kepala bagian) kini bertambah menjadi 12 (dua belas) orang dan pejabat eselon IV ( kepala sub bagian) yang sebelumnya hanya 27 (dua puluh tujuh) orang menjadi 36 ( tiga puluh enam ) orang.

Selain mengacu pada regulasi penataan PD, pembentukan sebuah struktur organisasi yang baik perlu disertai dengan sebuah analisis jabatan (job analysis) (Simangunsong, 2001). Hal ini dilakukan agar memperoleh klasifikasi jenis pekerjaan dan kriteria orang yang kompeten menangani hal tersebut. Adapun hasil analisis jabatan dapat menguraikan deskripsi jabatan (job analysis) dan spesifikasi jabatan (job spesification). Deskripsi jabatan merupakan uraian tertulis yang menguraikan tugas, fungsi dan wewenang serta kondisi kerja sedangkan spesifikasi jabatan menunjukkan siapa yang melakukan pekerjaan dan syarat kompetensi individunya (Sedarmayanti, 2016).

Adapun hasil deskripsi jabatan dan spesifikasi jabatan pada Sekretariat Daerah Kabupaten Ende pasca restrukturisasi sesuai PP 18 Tahun 2016 adalah sebagai berikut :

Tabel 3. Kebutuhan Jumlah ASN berdasarkan Analisis Beban Kerja

\begin{tabular}{|l|l|r|r|r|r|}
\hline \multirow{2}{*}{ No } & \multicolumn{1}{|c|}{ Nama Bagian } & \multirow{2}{*}{\begin{tabular}{c} 
Jumlah \\
Beban \\
\cline { 5 - 6 }
\end{tabular}} & & \multicolumn{3}{|c|}{ Jumlah Pegawai } \\
\cline { 5 - 6 } & & 44,57 & 15 & 12 & -3 \\
\hline 1 & Kerja & Kebutuhan & Existing & Keterangan \\
\hline 2 & $\begin{array}{l}\text { Pemerintahan dan } \\
\text { Otonomi Daerah }\end{array}$ & 45,66 & 16 & 10 & -4 \\
\hline
\end{tabular}




\begin{tabular}{|l|l|c|c|c|c|}
\hline 3. & Kesejahteraan Rakyat & 42,25 & 12 & 9 & -3 \\
\hline 4 & Hukum & 45,76 & 16 & 15 & -1 \\
\hline 5 & $\begin{array}{l}\text { Pemberdayaan } \\
\text { masyarakat dan } \\
\text { Trantibum }\end{array}$ & 42,36 & 12 & 8 & -4 \\
\hline 6 & Ekonomi & 45,65 & 16 & 9 & -3 \\
\hline 7 & Humas dan Protokoler & 49,82 & 22 & 18 & -4 \\
\hline 8 & $\begin{array}{l}\text { Administrasi } \\
\text { Pembangunan }\end{array}$ & 46,76 & 17 & 12 & -5 \\
\hline 9 & $\begin{array}{l}\text { Pengadaan Barang dan } \\
\text { Jasa }\end{array}$ & 47,54 & 18 & 7 & -11 \\
\hline 10 & Organisasi & 45,65 & 16 & 9 & -7 \\
\hline 11 & Umum & 50,87 & 25 & 28 & +3 \\
\hline 12 & Keuangan dan Aset & 48,76 & 19 & 15 & -4 \\
\hline
\end{tabular}

Sumber : Bagian Organisasi Tahun 2017

Berdasarkan tabel diatas dapat diketahui bahwa terdapat ketimpangan yang besar antara kebutuhan dan ketersediaan pegawai dalam menunjang kinerja Sekretariat Daerah Kabupaten Ende. Proses restrukturisasi yang terjadi tanpa memperhitungkan ketersediaan SDM aparatur membuat banyak kekurangan SDM pada 11 bagian yang ada.

\section{Integrasi Infrastruktur Fisik ( Configuring the Physical Infrastructure)}

Pembenahan infrastruktur fisik (configuring the physical infrastructure) merupakan upaya mengintegrasikan seluruh infrastruktur fisik yang dimiliki dan yang akan menjadi salah satu ukuran yang sangat penting terhadap arah dan strategi suatu organisasi. Penambahan jumlah fungsi organisasi dalam struktur organisasi akan berdampak pada ketersediaan infra struktur.

Sebagaimana diketahui sebelumnya bahwa struktur Sekretariat Daerah Kabupaten Ende telah mengalami pengembangan sesuai PP 18 Tahun 2016 tentang Perangkat Daerah. Pengembangan itu terletak pada penambahan 3 bagian baru yakni bagian kepegawaian, bagian pengadaan barang dan jasa serta bagian keuangan dan aset. Dengan adanya pengembangan bagian tersebut menegaskan pemisahan fungsi yang sebelumnya tergabung dalam struktur dimana keuangan/aset adalah pengembangan bagian umum, bagian pengadaan barang/jasa adalah pengembangan bagian administrasi pembangunan sedangkan bagian kepegawaian adalah pengembangan dari bagian organisasi. Konsekuensi fisik dari hal ini adalah bertambahnya bangunan atau ruangan kerja, peralatan dan perlengkapan gedung kantor dan kendaraan operasional.

Berdasarkan hasil temuan di lapangan terlihat bahwa masih banyak terjadi kekurangan sarana dan pra sarana kerja, terutama untuk unit/bagian hasil restrukturisasi berupa bangunan atau ruangan kerja, peralatan dan kelengkapan kerja . Sesuai hasil wawancara, maka kebijakan inventarisasi aset dan perencanaan pengadaan secara bertahap menjadi pilihan utama dalam memenuhi kebutuhan sarana dan pra sarana kerja pada bagian yang baru dibentuk. Porsi utama belanja modal digunakan untuk membiayai pengadaan fasilitas kerja secara bertahap . Hal ini tentunya menggerus porsi belanja publik Sekertariat Daerah Kabupaten Ende dan merupakan salah satu imbas negatif dari penambahan struktur organisasi pada Sekertariat Daerah Kabupaten Ende. 
3. Mendesain kembali arsitektur kerja (Redesign Work Architecture)

Suatu pekerjaan di dalam organisasi, diselesaikan melalui proses jaringan yang kompleks yang dalam hal ini disebut sebagai work architecture. Jaringan yang kompleks dalam organisasi jika dikonfigurasikan dengan benar oleh seperangkat tujuan dan ukuran dalam bentuk Standar Operasional Prosedur (SOP) yang terintegrasi maka akan menghasilkan simponi yang baik (Gouilarrt \& Kelly, 1995 ; Simanunsong, 2001).

Berdasarkan uraian diatas, maka SOP memiliki peranan penting dalam memastikan segala tindakan yang dilakukan dalam organisasi, khususnya pada organisasi pemerintah. Namun hal yang berbeda penulis temukan di Sekretariat Daerah Kabupaten Ende . Berdasarkan wawancara terhadap beberapa informan terungkap bahwa sampai saat ini Sekretariat Daerah Kabupaten Ende belum memiliki SOP. Hal tersebut diungkapkan oleh Kepala Bagian Ekonomi bahwasanya sampai saat ini belum ada perintah atasan untuk pembuatan SOP dan pelaksanaan tugas dilakukan hanya berpedoman pada Peraturan Bupati Ende Nomor 34 tahun 2016 tentang Kedudukan dan Susunan Tugas Pokok dan Fungsi Organisasi Sekretariat Daerah Kabupaten Ende.

Dari hasil pengamatan penulis juga menemukan kenyataan bahwa pelaksanaan tugas dilaksanakan sesuai kebiasaan/rutinitas yang ada dan merupakan hal yang sering dilakukan, sehingga para staff telah terbiasa dengan kondisi yang sama dan berlangsung bertahun-tahun. Ketidakpatuhan dalam pembuatan SOP untuk semua bagian di Sekretariat Daerah terus berlanjut walaupun telah dikeluarkan edaran untuk pembuatan SOP semenjak tahun 2015, bahkan menurut pengakuan Kepala Bagian Organisasi sering disuarakan dalam rapat internal atau rapat koordinasi. Namun banyak instansi yang belum menaatinya, termasuk Sekretariat Daerah Kabupaten Ende. Belum adanya kesadaran di kalangan aparatur dan kebijakan reward and punishment dari pimpinan membuat kebijakan SOP belum terlaksana dengan baik.

\section{SIMPULAN}

Restrukturisasi organisasi pada Sekertariat Daerah Kabupaten Ende dengan fokus pada dimensi membangun model organisasi, integrasi infrastruktur fisik, dan mendesain kembali arsitektur kerja belum berjalan secara efektif.

Pelaksanaan restrukturisasi pada Sekertariat Daerah Kabupaten akan berjalan dengan baik apabila menjalankan prosedur analisis beban kerja (ABK) dan SOP (Standar Operasional Prosedur) dengan baik, serta mengoptimalkan pemanfaatan Sumber Daya Manusia aparatur dan keuangan .

\section{REFERENSI}

Bennis \& Mische, w. a. M., 2005. The 21th Century Organization, Reinventing through Engineering. Kuala Lumpur: Golden Books Center.

Gouilarrt \& Kelly, F. J., 1995. Transforming the Organization. New York: Mc Graw- Hill.

Indrajit, R. E., 2006. Electronic Government. Yogyakarta: Andi.

Koentjaraningrat, 1991. Metode Penelitian Masyarakat. Jakarta: Gramedia.

Miles, M. B. \& Huberman, A. M., 1994. Qualitative Data Analysis, Second Edition. London, New Delhi: SAGE Publications.

Sedarmayanti, 2016. Manajemen Sumber Daya Manusia. BAndung: PT Refika Aditama. 
Simangunsong, F., 2001. Transformasi Organisasi: Perubahan. Bandung: Alfabeta.

Wasistiono, S., 2002. Manajemen Sumber Daya Aparatur Pemerintah Daerah.. Bandung: Alfabeta. 